\title{
A Comparison of Thermospheric Winds and Temperatures from Fabry-Perot Interferometer and EISCAT Radar Measurements with Models
}

\author{
M. J. Kosch ${ }^{1}$, M. Ishii ${ }^{2}$, S. Nozawa ${ }^{3}$, D. Rees ${ }^{4}$, K. Cierpka ${ }^{1}$, A. Kohsiek ${ }^{1}$, K. Schlegel ${ }^{1}$, R. Fujii ${ }^{3}$, T. Hagfors $^{1}$, \\ T. J. Fuller-Rowell ${ }^{5}$ and C. Lathuillere ${ }^{6}$ \\ ${ }^{1}$ Max-Planck-Institut für Aeronomie, Max-Planck-Str. 2, 37191 Katlenburg-Lindau, Germany. \\ ${ }^{2}$ Communications Research Laboratory,4-2-1 Nukui-Kitamachi, Koganei, Tokyo 184, Japan. \\ ${ }^{3}$ Solar-Terrestrial Environment Laboratory, Chikusa, Nagoya 464-01, Japan. \\ ${ }^{4}$ Center for Atmospheric and Space Science, Utah State University, Logan, UT 84322-4405, USA. \\ ${ }^{5}$ NOAA, Space Environment Laboratory, 325 Broadway, Boulder, Colorado 80303, USA. \\ ${ }^{6}$ LIS/ENSIEG, BP 46, 38402 Saint Martin d'Heres CEDEX, France.
}

\begin{abstract}
During the nights of 8-9 and 9-10 February 1997, Fabry-Perot interferometers were operated from the EISCAT radar site at Ramfjord $\left(69.59^{\circ} \mathrm{N}, 19.23^{\circ} \mathrm{E}\right)$ and Skibotn $\left(69.35^{\circ} \mathrm{N}, 20.36^{\circ} \mathrm{E}\right)$. From Ramfjord, horizontal neutral winds were measured in the lower and upper thermosphere using the auroral/airglow emissions at 557.7 and 630 $\mathrm{nm}$, respectively. From Skibotn, thermospheric neutral temperatures were measured using the same wavelengths. The EISCAT radar measured ion temperatures up the local magnetic field line in the height range $90-580 \mathrm{~km}$ during the first night. Neutral winds are compared to the HWM-90 and CTIP-200 models with poor agreement. Neutral temperatures are compared to the MSISE-90 and CTIP-200 models as well as EISCAT ion temperatures with good agreement.
\end{abstract}

\section{INTRODUCTION}

During the nights of 8-9 and 9-10 February 1997, Fabry-Perot interferometers (FPI) were operated in northern Scandinavia from the EISCAT radar site at Ramfjord $\left(69.59^{\circ} \mathrm{N}, 19.23^{\circ} \mathrm{E}\right)$ and Skibotn $\left(69.35^{\circ} \mathrm{N}, 20.36^{\circ} \mathrm{E}\right)$, about $50 \mathrm{~km}$ away. From Ramfjord, horizontal neutral winds were measured in the lower and upper thermosphere using the Doppler shift of auroral/airglow emissions at 557.7 and $630 \mathrm{~nm}$, respectively. The Japanese interferometer (Ishii et al., 1997) is a Doppler Imaging System (DIS) (Rees and Greenaway, 1983; Rees et al., 1984) employing a wide field of view with 2 detectors. It is capable of estimating Doppler shifts over most of the sky at both wavelengths simultaneously. Using the fringe which maps to an elevation angle of $\sim 45^{\circ}$, Doppler shifts for all azimuths are combined to produce an equivalent mean horizontal wind approximately every minute. A running average of 5 minutes is used to smooth the result. From Skibotn, thermospheric neutral temperatures were measured in the local zenith from the Doppler broadening of the same wavelengths using $60 \mathrm{~s}$ integration. The German FPI (Kosch et al., 1997a, 1997b) has a single detector employing a narrrow field of view orientated with a steerable mirror. Due to sequential scanning of the sky (for purposes not presented here) and wavelengths, the measurement cycle is about 16 minutes. The effective altitude in the lower $(557.7 \mathrm{~nm})$ and upper $(630 \mathrm{~nm})$ thermosphere corresponds to approximately 115 (Störmer, 1955) and 240 (Sica et al., 1986; Solomon et al., 1988) $\mathrm{km}$, respectively. The EISCAT incoherent backscatter radar (Rishbeth and van Eyken, 1993) was measuring up the local magnetic field line in the height range $90-580 \mathrm{~km}$ during the first part of the first night only. Ion temperatures with 5 minute averaging have been extracted.

MSISE-90 (Hedin, 1991) is a global analytic empirical model of the atmosphere for various geophysical conditions, extending from the ground well into the exosphere. Here, average neutral temperatures are extracted. HWM-90 (Hedin et al., 1991) is a global analytic empirical model of neutral winds in the atmosphere for various 
geophysical conditions, extending from 100 km altitude upwards. CTIP-200 (Fuller-Rowell and Rees, 1980; Millward et al., 1996) is a global, 3-dimensional, time-dependant numerical model which simulates the dynamical behaviour of the thermosphere under a wide variety of geophysical conditions. In this study, neutral winds, neutral temperatures and ion temperatures are computed using global energy input estimates based on the 3-hour Kp index (Forster et al., 1986). Since this model works in 15 pressure levels spread over 80-450 km, the altitude varies slightly throughout the simulation. The spatial resolution is $2^{\circ}$ latitude and $18^{\circ}$ longitude.

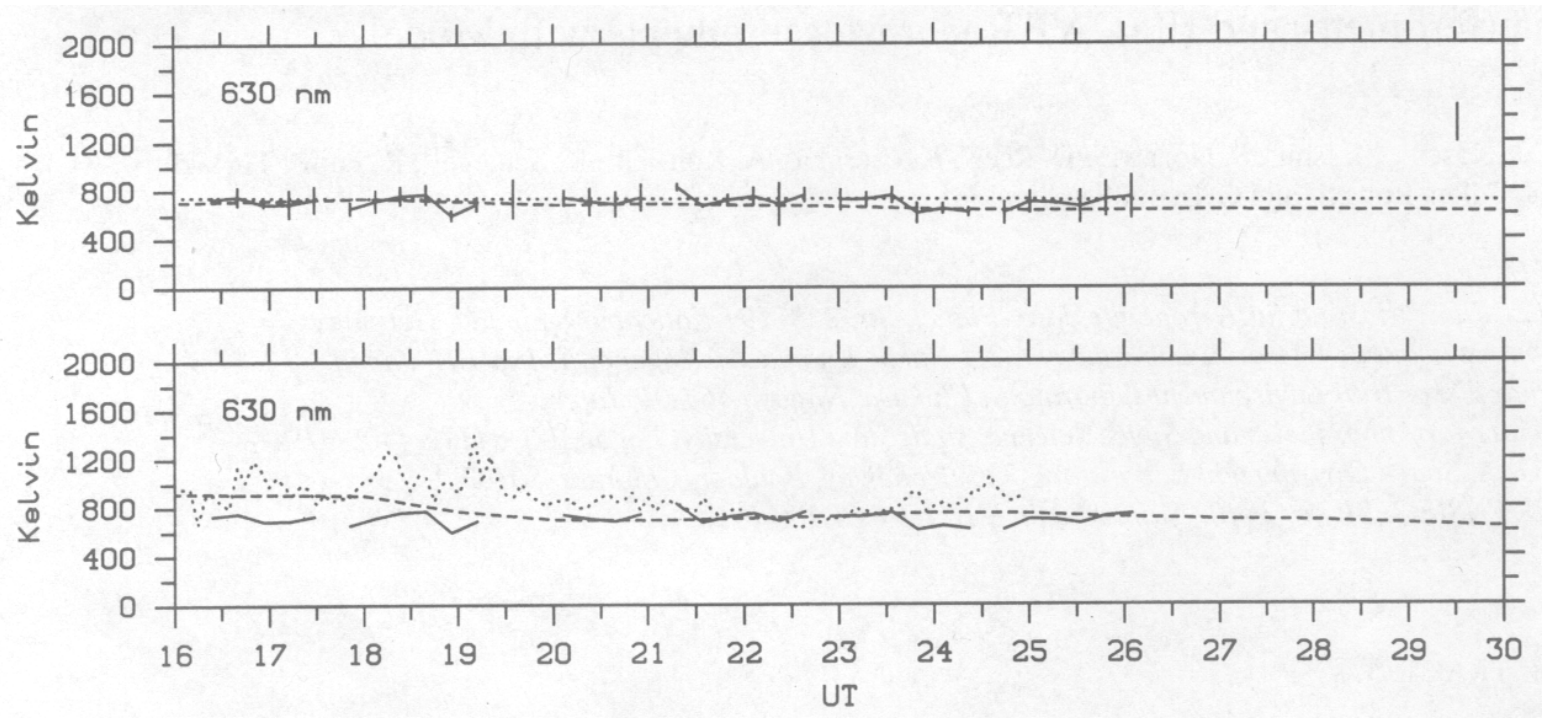

Fig. 1. Upper thermosphere neutral and ion temperatures for 8-9/2/97. The top panel shows neutral temperatures from the Skibotn FPI at $630 \mathrm{~nm}$ (solid curve) and modelling results from MSISE-90 at $240 \mathrm{~km}$ (dotted curve) and CTIP-200 at $250 \mathrm{~km}$ (dashed curve). The bottom panel shows the same FPI neutral temperatures at $630 \mathrm{~nm}$ (solid curve) and ion temperatures from EISCAT averaged over 231-253 km (dotted curve) and the CTIP-200 model at $\sim 250 \mathrm{~km}$ (dashed curve).

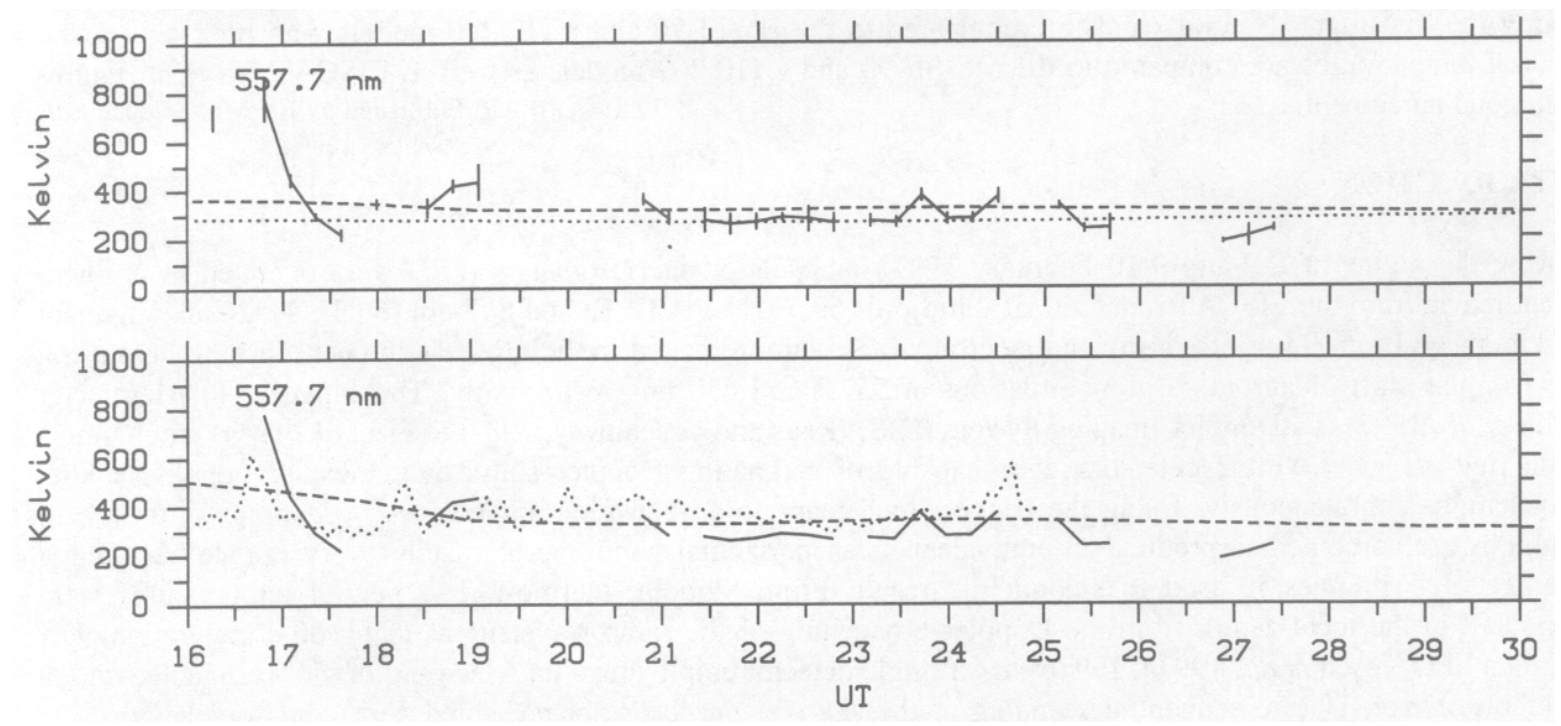

Fig. 2. Lower thermosphere neutral and ion temperatures for 8-9/2/97. The top panel shows neutral temperatures from the Skibotn FPI at $557.7 \mathrm{~nm}$ (solid curve) and modelling results from MSISE-90 at $115 \mathrm{~km}$ (dotted curve) and CTIP-200 at $115 \mathrm{~km}$ (dashed curve). The bottom panel shows the same FPI neutral temperatures at $557.7 \mathrm{~nm}$ (solid curve) and ion temperatures from EISCAT averaged over 115-121 km (dotted curve) and the CTIP-200 model at $115 \mathrm{~km}$ (dashed curve). 
Reference is made to thermospheric observations at $630 \mathrm{~nm}$ by the French Michelson interferometer (MICADO) (Thuillier et al., 1990). Observations were made during the solar maximum winters of 1988-1991 in conjunction with EISCAT campaigns from Sodankylä, Finland $\left(67.37^{\circ} \mathrm{N}, 26.63^{\circ} \mathrm{E}\right)$, about $390 \mathrm{~km}$ from Ramfjord. An important difference is that we report results from solar minimum. The first night investigated here was geomagnetically disturbed $\left(\mathrm{Kp}=4^{-}-5^{\circ}\right)$ prior to magnetic midnight $(\approx 21: 30 \mathrm{UT})$ but much quieter thereafter $(\mathrm{Kp}$ $\left.=2^{0}-2^{+}\right)$. The second night was geomagnetically active throughout $\left(\mathrm{Kp}=4^{-}-5^{+}\right)$, especially around magnetic midnight.

\section{RESULTS}

Figure 1 shows the upper thermosphere neutral and ion temperatures for the night of 8-9/2/97. The top panel shows neutral temperatures from the Skibotn FPI at $630 \mathrm{~nm}$ (solid curve), with error bars, and modelling results from MSISE-90 at $240 \mathrm{~km}$ (dotted curve) and CTIP-200 at 250 km (dashed curve). Measured and modelled neutral temperatures are in good agreement. The bottom panel shows the same FPI neutral temperatures again (solid curve) but with ion temperatures from EISCAT averaged over 231-253 km (dotted curve) and the CTIP-200 model at $\sim 250 \mathrm{~km}$ (dashed curve). The model is a good approximation of the measured ion temperature given it's low spatial resolution and the low time resolution for energy input when compared to EISCAT's real time point measurement.

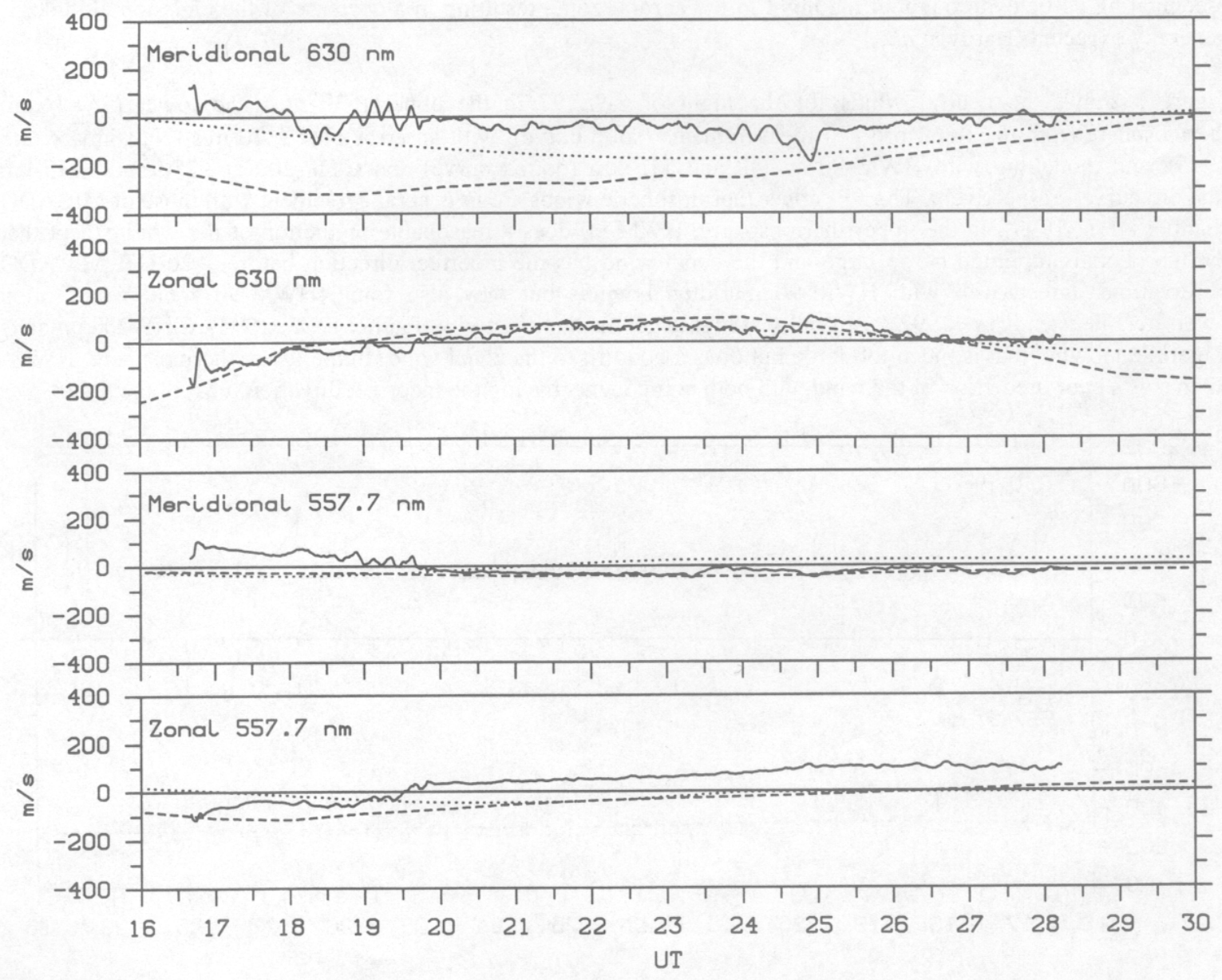

Fig. 3. Neutral winds for 8-9/2/97 in the upper $(630 \mathrm{~nm})$ and lower $(557.7 \mathrm{~nm})$ thermosphere from the Ramfjord FPI measurements (solid curve) and modelling with HWM-90 at 240 and $115 \mathrm{~km}$ (dotted curve) and CTIP-200 at $\sim 250$ and $\sim 115 \mathrm{~km}$ (dashed curve), respectively. Northward and Eastward are positive. The measured wind error is $< \pm 10 \mathrm{~m} / \mathrm{s}$.

It is expected that the ion temperature should be greater than or equal to the neutral temperature, the difference being primarily due to ion heating by ionospheric electric fields (Lockwood et al., 1993). Figure 1 shows this 
clearly with a large difference prior to $21 \mathrm{UT}$ when $\mathrm{Kp}=4^{-}-5^{\circ}$ and much closer agreement after $21 \mathrm{UT}$ when $\mathrm{Kp}=$ $2^{0}-2^{+}$. Unfortunately, no quantitative comparison is possible since EISCAT did not measure electric fields at this time due to a technical fault. Our results are entirely consistent with MICADO (Thuillier et al., 1990).

Figure 2 shows the lower thermosphere neutral and ion temperatures for the night of 8-9/2/97. The top panel shows neutral temperatures from the Skibotn FPI at $557.7 \mathrm{~nm}$ (solid curve), with error bars, and modelling results from MSISE-90 at $115 \mathrm{~km}$ (dotted curve) and CTIP-200 at $115 \mathrm{~km}$ (dashed curve). Measured and modelled neutral temperatures are in good agreement. The bottom panel shows the same FPI neutral temperatures again (solid curve) but with ion temperatures from EISCAT averaged over 115-121 km (dotted curve) and the CTIP-200 model at $\sim 115 \mathrm{~km}$ (dashed curve). Again, the model is a good approximation of the measured ion temperature. Given the increase in ion-neutral collision frequency of some 2 orders of magnitude at lower altitudes (Kelley, 1989), the difference between ion and neutral temperatures is expected to be small. The problem with the FPI measurement at $557.7 \mathrm{~nm}$ is the unknown height of the emission which can be very variable in the auroral zone. Figure 2 shows neutral and ion temperatures in good agreement, however, neutral temperatures are greater than ion temperatures before 20 UT and vice versa after 20 UT. A more detailed analysis (not shown) indicates that the emission had an effectively height of $>121 \mathrm{~km}$ before 20 UT and $<115 \mathrm{~km}$ after 20 UT. A hardening of the energy spectrum of the precipitating particles throughout the night in the auroral zone, resulting in a decrease of the emission altitude, is generally expected (Hardy et al., 1985).

Figure 3 shows the neutral winds for the night of 8-9/2/97 in the upper $(630 \mathrm{~nm})$ and lower $(557.7 \mathrm{~nm})$ thermosphere from the Ramfjord FPI measurements (solid curve), with an error of $< \pm 10 \mathrm{~m} / \mathrm{s}$ (Nakajima et al., 1995), and modelling with HWM-90 at 240 and $115 \mathrm{~km}$ (dotted curve) and CTIP-200 at 250 and $115 \mathrm{~km}$ (dashed curve), respectively. The FPI upper thermospheric winds are in general agreement with those of MICADO (Fauliot et al., 1993). In the upper thermosphere, HWM-90 does a reasonable prediction of the wind except that the meridional amplitude is too large and the zonal wind has the incorrect direction before $\sim 20$ UT. MICADO observations agreed well with HWM-90 meridional winds but they also found HWM-90 zonal winds often reversed (Lilensten et al., 1992), especially at higher geomagnetic activity (Fauliot et al., 1993). CTIP-200 predicts a meridional wind that is much too large but does a good fit to the zonal wind. In the lower thermosphere, HWM90 makes a poor prediction of the wind with both components having the incorrect direction most of the time.

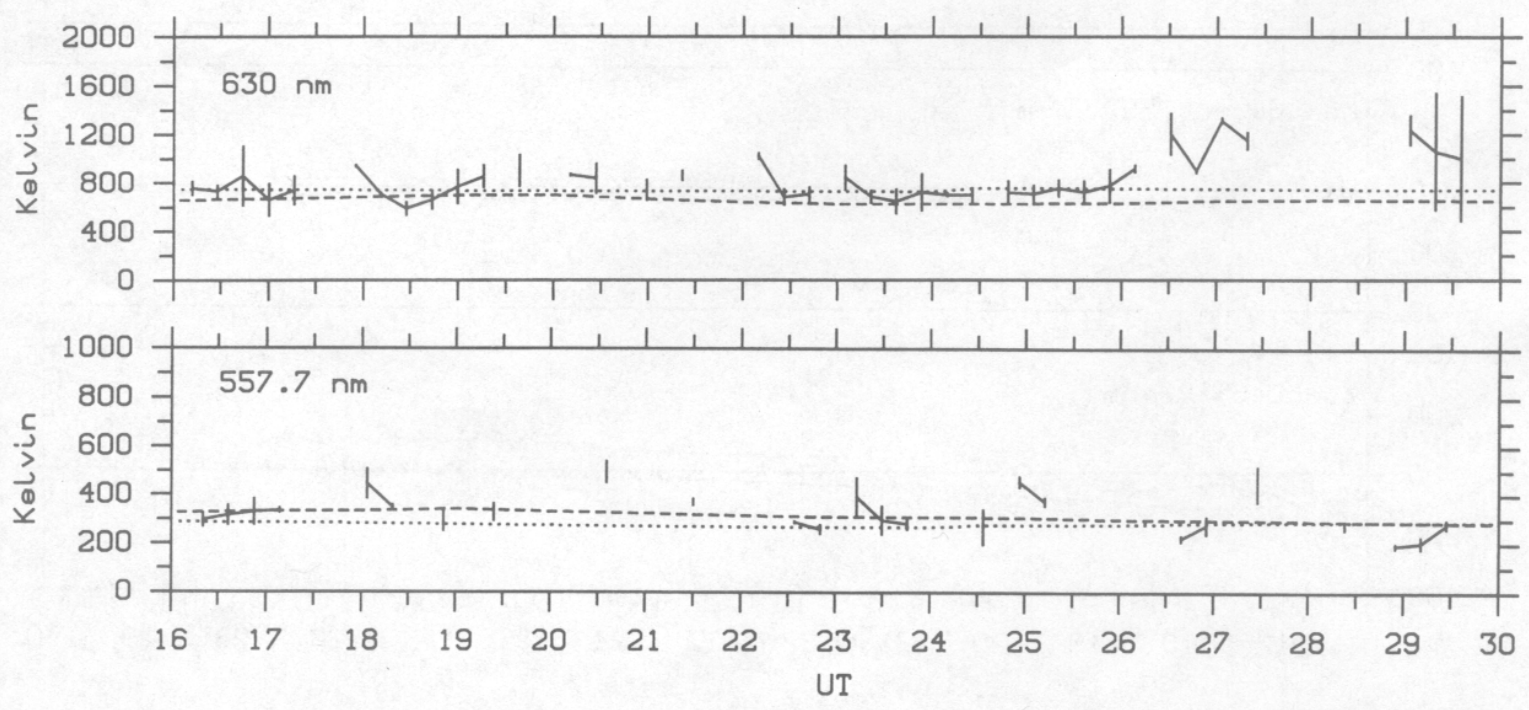

Fig. 4. Upper $(630 \mathrm{~nm})$ and lower $(557.7 \mathrm{~nm})$ thermosphere neutral temperatures for 9-10/2/97 from the Skibotn FPI measurements (solid curve) and modelling with MSISE-90 at 240 and $115 \mathrm{~km}$ (dotted curve) and CTIP-200 at $\sim 250$ and $115 \mathrm{~km}$ (dashed curve), respectively. 
CTIP-200 performs better but has the incorrect meridional direction before $\sim 20$ UT. The zonal wind has the correct basic shape but is offset by $\sim 100 \mathrm{~m} / \mathrm{s}$ Westward. It is clear that both models require improvement at both altitudes on this day.

Figure 4 shows upper and lower thermosphere neutral temperatures for the night of 9-10/2/97 from the Skibotn FPI. No EISCAT data was available. The top panel shows neutral temperatures from $630 \mathrm{~nm}$ (solid curve), with error bars, and modelling results from MSISE-90 at $240 \mathrm{~km}$ (dotted curve) and CTIP-200 at $250 \mathrm{~km}$ (dashed curve). The bottom panel shows neutral temperatures from $557.7 \mathrm{~nm}$ (solid curve), with error bars, and modelling results from MSISE-90 at $115 \mathrm{~km}$ (dotted curve) and CTIP-200 at $115 \mathrm{~km}$ (dashed curve). Again, measured and modelled neutral temperatures are mostly in good agreement. The decrease in emission altitude (see Figure 2) for $557.7 \mathrm{~nm}$ is not clear here due to the high level of auroral activity. The large data gaps prior to local midnight are caused by detector over-saturation due to strong auroral displays. After local midnight, data gaps are due to a very weak emission intensity, also resulting in the large error bars in $630 \mathrm{~nm}$ at the end of the night.

Figure 5 shows the neutral winds for the night of 9-10/2/97 in the upper $(630 \mathrm{~nm})$ and lower $(557.7 \mathrm{~nm})$ thermosphere from the Ramfjord FPI measurements (solid curve), with an error of $< \pm 10 \mathrm{~m} / \mathrm{s}$ (Nakajima et al., 1995), and modelling with HWM-90 at 240 and $115 \mathrm{~km}$ (dotted curve) and CTIP-200 at 250 and $115 \mathrm{~km}$ (dashed curve), respectively. In the upper thermosphere, HWM-90 does a good prediction of the meridional wind but the zonal wind has the incorrect direction before 20 UT. CTIP-200 predicts the correct basic shape for both

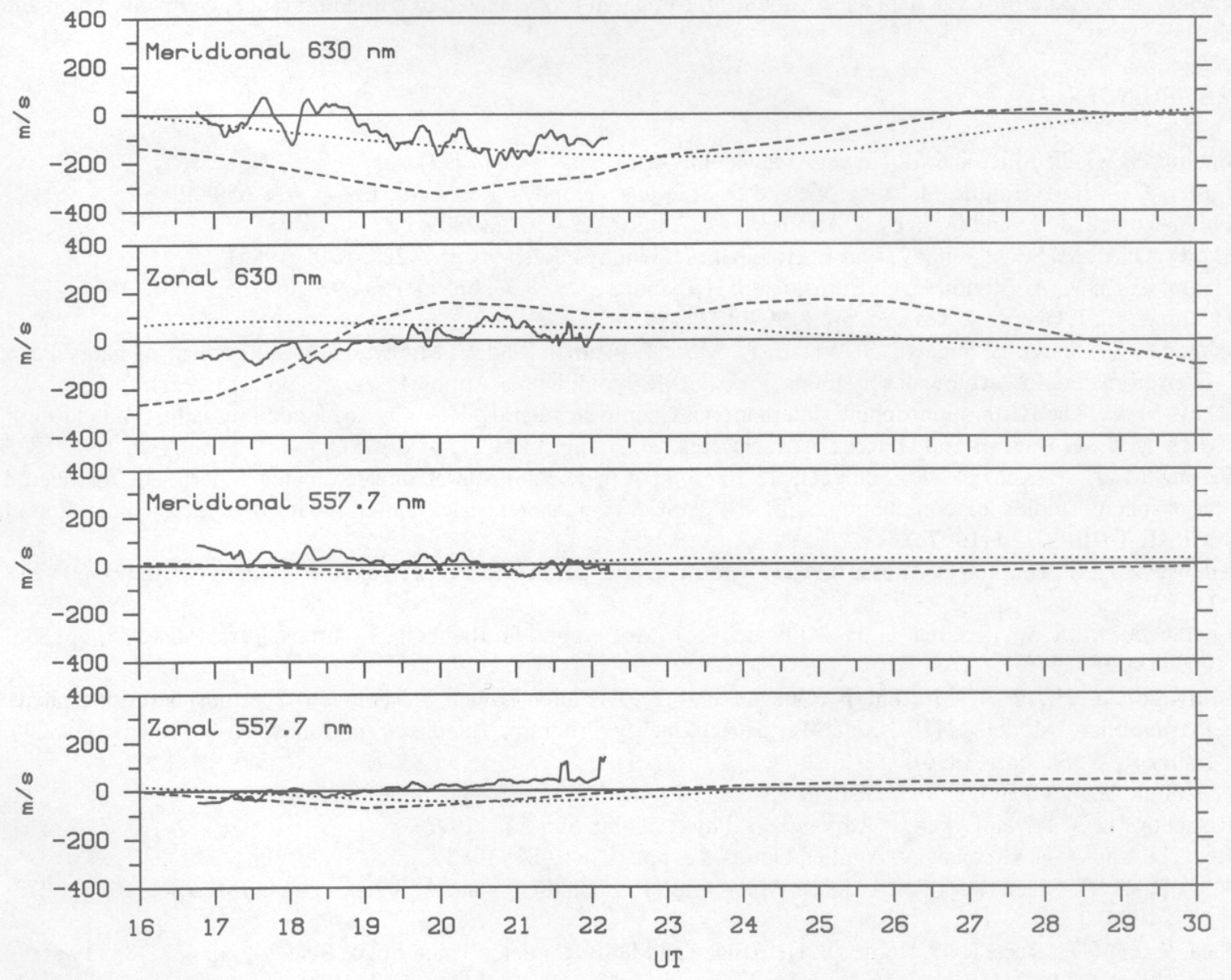

Fig. 5. Neutral winds for 9-10/2/97 in the upper (630 nm) and lower (557.7 $\mathrm{nm}$ ) thermosphere from the Ramfjord FPI measurements (solid curve) and modelling with HWM-90 at 115 and $240 \mathrm{~km}$ (dotted curve) and CTIP-200 at $\sim 115$ and $\sim 250 \mathrm{~km}$ (dashed curve), respectively. Northward and Eastward are positive. The measured wind error is $< \pm 10 \mathrm{~m} / \mathrm{s}$. 
components but with too large an amplitude. In the lower thermosphere, HWM-90 makes a poor prediction of the wind with both components having the incorrect direction most of the time. CTIP-200 performs better but also has the incorrect direction for the zonal component before 22 UT. The meridional component has the correct basic shape but is offset by $\sim 50 \mathrm{~m} / \mathrm{s}$ southward. Again, both models require improvement at both altitudes for this day.

\section{CONCLUSIONS}

From 2 nights of observations (8-10 February 1997) in northern Scandinavia the following may be concluded. FPI neutral temperature measurements from Skibotn are in good agreement with EISCAT ion temperatures as well as the MSISE-90 and CTIP-200 models. FPI wind measurements from Ramfjord illustrate significant discrepancies with the HWM-90 and CTIP-200 model predictions in both the upper and lower thermosphere. Although models may not always perform well in the auroral zone, due to short term localised energy inputs resulting from geomagnetic substorms and auroral displays, room for improvement remains.

\section{ACKNOWLEGEMENTS}

EISCAT is supported by Suomen Akatemia (Finland), Centre Nationale de la Recherche Scientifique (France), Max-Planck-Gesellschaft (Germany), the National Institute of Polar Research (Japan), Norges forskningsrådet (Norway), Naturvetenskapliga forskningsrådet (Sweden) and the Particle Physics and Astronomy Research Council (UK). The EISCAT data used came from campaign time donated by Finland, France, Germany, Japan and the UK.

\section{REFERENCES}

Fauliot, V., G. Thuillier and M. Herse, Ann. Geophys., 11, pp. 17-28 (1993).

Foster, J. C., J. M. Holt, R. G. Musgrove and D. S. Evans, Geophys. Res. Lett., 13, pp. 656-659 (1986).

Fuller-Rowell, T. J., and D. Rees, J. Atmos. Sci., 37, pp. 2545-2567 (1980).

Hardy, D. A., M. S. Gussenhove and E. Holeman, J. Geophys. Res., 90, pp. 4229-4248 (1985).

Hedin, A. E., M. A. Blondi, R. G. Burnside, G. Hernandez et al., J. Geophys. Res., 96, pp. 7657-7688 (1991).

Hedin, A. E., J. Geophys. Res., 96, pp. 1159-1172 (1991).

Ishii, M., S. Okano, E. Sagawa, S. Watari, H. Mori, I. Iwamoto and Y. Murayama, Development of Fabry-Perot interferometers for airglow observations, Proc. NIPR Symp. Upper Atmos. Phys., 10, pp. 97 (1997).

Kelly, M. C., The Earth’s Ionosphere, International Geophysics Series, Vol. 43, Academic Press, pp. 34-35 (1989).

Kosch, M. J., T. Hagfors and D. Rees, Adv. Sp. Res., 20(6), pp. 1133-1136 (1997a).

Kosch, M. J. A. Kohsiek, K. Schlegel, T. Hagfors, A new Fabry-Perot interferometer experiment for neutral atmosphere studies in conjunction with the EISCAT incoherent-backscatter radar system, Techical Report MPAE-T-010-97-20 (1997b).

Lilensten, J., G. Thuillier, C. Lathuilere, W. Kofman, V. Fauliot and M. Merse, Ann. Geophys., 10, pp. 603-618 (1992).

Lockwood, M., I. W. McCrea, G. H. Millward, R. J. Moffett and H. Rishbeth, J. Atmos. Terr. Phys., 55, pp. 895906 (1993).

Millward, G. H., R. J. Moffett, S. Quegan and T. J. Fuller-Rowell, A coupled Thermosphere-IonospherePlasmasphere Model (CTIP), Solar-Terrestrial Energy Program: Handbook of Ionospheric Models, pp. 239, Editor R. W. Schunk (1996).

Nakajima, H., S. Okano, H. Fukunishi and T. Ono, Applied Optics, 34, pp. 8382-8395 (1995).

Rishbeth, H., A. P. van Eyken, J. Atmos. Terr. Phys., 55, pp. 525-542 (1993).

Rees, D., and A. H. Greenaway, Applied Optics, 22, pp. 1078-1083 (1983).

Rees, D., A. H. Greenaway, R. Gordon, I. McWhirter, P. J. Charleton and Å. Steen, Planet. Space Sci., 32, pp. 273285 (1984).

Sica, R. J., M. H. Rees, R. G. Roble, G. Hernandez and G. J. Romick, Planet. Space Sci., 24, pp. 483-488 (1986).

Solomon, S. C., P. B. Hays and V. J. Abreu, J. Geophys. Res., 93, pp. 9867-9882 (1988).

Störmer, C., The Polar Aurora, Oxford Univ. Press (Clarendon), London and New York, pp. 67-80 (1955).

Thuillier, G., C. Lathuilere, M. Herse, C. Senior, W. Kofman et al., J. Atmos. Terr. Phys., 52, pp. 625-636 (1990). 